\title{
Aspectual perspective taking in event construal in L1 and L2 Dutch
}

\author{
GERCOLINE VAN BEEK, MONIQUE FLECKEN AND MARIANNE STARREN
}

\begin{abstract}
The present study focuses on the role of grammatical aspect in event construal and its function in encoding the specificity of an event. We investigate whether advanced L2 learners (L1 German) acquire target-like patterns of use of progressive aspect in Dutch, a language in which use of aspect depends on specific situation types. We analyze use of progressive markers and patterns in information selection, relating to specific features of agents or actions in dynamic event scenes. L2 event descriptions are compared with L1 Dutch and L1 German data. The L2 users display the complex situation-dependent patterns of use of aspect in Dutch, but they do not select the aspectual viewpoint (aan het construction) to the same extent as native speakers. Moreover, the encoding of specificity of the events (mentioning of specific agent and action features) reflects $L 1$ transfer, as well as target-like performance in specific domains.
\end{abstract}

\section{Introduction}

Second language (L2) acquisition is often viewed as the process of learning the phonological, morphological, syntactic, and semantic aspects of a specific language. However, even when people speak a second language (L2) fluently and grammatically correctly, the speech of advanced L2 users is often perceived as non-native by native speakers of a given language (Larsen-Freeman 1991; von Stutterheim 2003; von Stutterheim and Carroll 2006). ${ }^{1}$ In order to be per-

1. The term second language (L2) user (Cook, 2002) is used interchangeably with L2 speaker, L2 speaker, as well as (late) bilingual. All terms are neutral with respect to the specific L2 proficiency level of the speaker, and refer to speakers who have started acquiring the L2 in or after puberty. When speaking of early bilinguals, we refer to bilingual speakers who have started acquiring both languages before the age of three. 
ceived as a native speaker, it is not only necessary to speak a language in a grammatically correct form, but also to structure and organize information in a way that is typical for the target language. Typical patterns in conceptualizing and organizing information with respect to situations or events can be traced back to the specific linguistic means that a language offers ("thinking for speaking" processes, see 2.1). In particular, certain grammatical categories play a relevant role in the early processes of language production, the phase of conceptualization, during which information is segmented and selected, and a particular perspective is taken on a situation or event (cf. Levelt 1989; von Stutterheim and Nüse 2003; see below). These patterns in construing events become deeply entrenched and highly automatized during the acquisition of one's native language (von Stutterheim 2003; Schmiedtová et al. 2011). Given a lack of adherence to target language-specific principles in information organization (von Stutterheim 2003; see below), the speech of even highly proficient L2 users may thus not be ungrammatical, but information selection and structure in sentences or longer stretches of discourse may not reflect the target language typical preferences in referring to situations or events.

Research on L2 users can thus address the question of how deeply entrenched native language preferences are in second language use. If such preferences are superficial, second language speakers may not have much difficulty in acquiring the information organization patterns of the target language. Studies on the question of ultimate attainment show that principles of information organization acquired through the L1 are difficult to 'restructure', when transferred in L2 acquisition ('restructuring' cf. Jarvis and Pavlenko 2008: the reorganization of conceptualization patterns, so that L2 users begin to resemble, at least partly, target-like patterns of performance). Such principles thus do not only relate to the acquisition and use of forms in the L2, they involve different operations at the level of conceptualization in language production (LarsenFreeman 1991; von Stutterheim 2003; Brown and Gullberg 2008; Jarvis and Pavlenko 2008).

The aim of the present paper is to look at patterns in event construal, relating to aspectual perspective taking (i.e., the use of progressive aspect) and what this entails for information structure, in particular the encoding of the specificity of an event. We investigate very advanced L2 users of Dutch (with L1 German). Descriptions of different event types will be analyzed and compared to those produced by native speakers of source and target language, thus shedding light on potential transfer effects. In our discussion, we relate our findings on advanced late bilingual speakers (acquisition of the L2 started in or after puberty) to previous studies on early German-Dutch bilinguals, as well as late English-Dutch bilinguals. 


\section{Background}

\section{1. "Thinking for speaking": Language-specific principles in information organization}

Many studies to date show how the specific inventory of a given language affects the way in which aspects of reality are interpreted and conceptualized when carrying out a verbal task (von Stutterheim 2003). Specifically, when talking about events or situations, planning longer stretches of discourse, grammatical linguistic structures serve "to connect events and syntactically "package' them into coherent structures" (Berman and Slobin 1994: 1-2). "[O]ne cannot verbalize experience without taking a perspective, and (...) the language being used often favors particular perspectives" (Slobin 2000: 107). Languages encode aspects of reality through different lexical and grammatical means; they thus provide different types of expressive devices to categorize and talk about specific elements of the world. The specific linguistic repertoire that a language offers thus induces particular patterns of thinking, which are activated during the act of speaking ("thinking for speaking", cf. Slobin, 1996). Grammaticalized categories, specifically, are deeply anchored in the linguistic system, and they give rise to highly automatized patterns or scaffolds, when selecting and structuring information for expression. Long-time use of these patterns results in the entrenchment of language-specific principles of information organization, which speakers implement, when solving complex verbal tasks (von Stutterheim 2003; Schmiedtová et al. 2011). Specifically relevant for the domain of events are different means to express concepts of space and time, two crucial domains that must be interrelated in event construal. The next section will specifically address cross-linguistic differences in the domain of time (grammatical aspect), and the implications of this linguistic category for encoding the specificity of an event.

\subsection{The role of grammatical aspect in event conceptualization}

Because events are situations in which concepts such as space, time, causality, and agency all play a role, research on language-specificity with regard to information organization has focused on event construal (see e.g., Bohnemeyer $\&$ Pederson, 2010). The conceptualization of time, in particular, has received a great deal of attention. Starren (2001) states that even at early phases of acquisition, speakers must contextualize or anchor in time events or states they are talking about with regard to whether an event occurs after, before, or at a point simultaneous to another one. Different languages have different linguistic means to embed events in temporal structures and to anchor them in time, 
as a result of different ways of encoding tense and aspect (Schmiedtová et al. 2011).

Looking specifically at the domain of motion events, a temporal concept that is well studied relates to the expression of "ongoingness" (i.e., progressive aspect). Previous studies have shown how the presence or absence of grammatical aspect in a linguistic system affects the particular perspective taken when describing goal-oriented motion events (Carroll et al. 2004; Bylund and Jarvis 2011; von Stutterheim et al. 2012). Speakers have the option of talking about a motion event in holistic terms, including mentioning of a goal (e.g., ein Auto fährt zu einem Dorf 'a car drives to a village'), or they may select a specific phase of the event, for example the intermediate phase (e.g., a car is driving through the country side) when the phase in question is focused and the endpoint is left ambiguous in the visual stimulus. It was found that these patterns in information selection are not random, but that the former pattern, holistic perspective taking, is preferred by speakers of languages without grammatical markers of progressive aspect (e.g., German, Norwegian, and Swedish), whereas the latter pattern in which event boundaries are defocused (Comrie 1976) was confirmed as occurring most frequently in aspect languages (e.g., English, Arabic, Spanish, and Russian) (Bylund 2009, 2011; Schmiedtova et al. 2011; von Stutterheim et al. 2012). These findings were taken to show how specific linguistic categories play a role in focusing speakers' attention to specific aspects of an event from the outset in the production process (i.e., while speakers are processing information in preparation for speech), thus indicating language-specific effects already during conceptualization in language production (von Stutterheim 2007; von Stutterheim et al. 2012). Speakers of languages in which an aspectual viewpoint is expressed obligatorily by means of verbal morphology are led to conceptualize and convey corresponding aspects of a dynamic situation, in this case the ongoing phase of the event. Specificity of the event, i.e., temporally anchoring the event to a specific reference time as opposed to marking the event as generic or habitual - is marked by means of progressive aspectual morphology on the verb (something is ongoing "right now", the semantic difference between dogs are barking [right now] and dogs bark [generic statement]). Speakers of languages that offer only lexical means to convey the same kind of information (e.g., German and Norwegian) do not focus on the ongoing phase to the same extent. Instead, they provide specificity by marking an endpoint in the specific case of motion events.

The literature on semantics provides an overview of the different means that languages provide to encode specificity (Dahl 1985; Krifka 1995). In nonaspect languages, such as German, unmarked verb forms show ambiguity with respect to specificity (e.g., ein Hund bellt 'a dog barks' [right now or generic fact]), and evidence from event description experiments shows that German speakers use other linguistic means to convey that the status of a causative 
event is specific (von Stutterheim et al. 2009; van Ierland 2010; Carroll and von Stutterheim 2011; Hilberink et al. in press). Such other means include the mentioning of specific characteristics of the entities involved in an event (e.g., visual characteristics of the agent, such as hair colour, age, or features of the objects or instruments involved, or the location at which an action or event takes place).

In summary, previous studies indicate that there is a specific interrelation between the marking of specificity of an event through extra-verbal material (such as adjectives or adjuncts) and the presence or absence of progressive aspect. Dutch represents an especially interesting case, as the language provides a morphological marker of progressive aspect, which is not fully grammaticalized, however (see Section 3.1 below). The present study looks at the question of aspect and specificity in L1 and L2 Dutch.

\section{3. "Thinking for speaking" in a second language}

Research on the acquisition of language-specific patterns in conceptualization has addressed the question as to how L2 speakers master the mapping between linguistic form and conceptual representation for specific event types in the L2. In other words, to what degree can L2 speakers acquire the knowledge that L1-specific "thinking for speaking" patterns are not compatible with those of the L2 (von Stutterheim 2003; von Stutterheim and Carroll 2006; Brown and Gullberg 2008; Bylund 2009; Schmiedtová et al. 2011). The crucial questions are thus whether the principles in information organization in an L2 can be acquired in the same way, or with the same success, as in the L1, and how L2 users deal with elements that their L1 in comparison to their L2 may contain, or lack (von Stutterheim 2003). Looking again at the domain of motion events, findings diverge. A main finding relates to the role of L2 proficiency. Schmiedtova et al. (2011) concluded that L1-specific thinking for speaking patterns, although present in the performance of advanced learners, play a particularly prominent role in initial and intermediate learners (Cadierno and Ruiz 2006; Schmiedtová et al. 2011). This indicates that an increase in L2 proficiency may reduce the transfer of information structure patterns from the L1 to the L2. Navarro and Nicoladis (2005) and Cadierno and Ruiz (2006), looking at cross-linguistic differences in the domain of motion events relating to verb lexicalization patterns (cf. Talmy 2000), found that the advanced L2 users in their sample still rely largely on L1 patterns when construing motion events in the L2. A pattern of conceptual transfer from the L1 (Czech, Russian) to motion event descriptions in the L2 (German) was also identified in Schmiedtová and Sahonenko (2008). Bylund (2009) and Bylund and Jarvis (2011) look at motion event construal in advanced Spanish learners of Swedish (when speak- 
ing Spanish) and they find that age of acquisition may also play a role in the acquisition of patterns in perspective-taking. The L2 users who had acquired Swedish before the age of 12 show 'restructuring' of Spanish patterns, and an L2 influence, i.e., a higher frequency of encoding of endpoints, in L1 motion event descriptions.

Evidence with regard to the influence of a speaker's L1 on performance in an L2, besides, for example, level of proficiency in the L2, has been found for factors relating to the specific typological profile of the first and the second language (see overview in Benazzo et al. 2012).

\section{Dutch}

\subsection{Progressive aspect and event construal in Dutch, German and English}

Whereas English has a grammaticalized marker of progressive aspect, German does not. German has forms that mark aspect, but they are lexical and highly constrained in use (Ebert 2000; Krause 2002; van Pottelberge 2004; some recent empirical studies von Stutterheim et al. 2009; Flecken 2011a; Los and Starren 2012). As progressive aspectual markers also have the function of grounding the event in time and space as a specific case, German speakers resort to different means to distinguish between situations going on at the time of speech, and generic or habitual situations (Carroll et al. 2004). When describing an ongoing event, German speakers may express that a situation is a specific situation, taking place in the here and now, by referring to certain features of the event that relate to the external world (i.e., specific characteristics of the entities involved in an event; see Section 2.2).

In Dutch, though, the situation is less clear and Dutch is sometimes characterized as being "in between English and German" with respect to its typological classification (see for example Vismans et al. 2010). The Dutch language has several forms to aspectually mark ongoingness. This can be denoted by constructions such as aan het (V-inf) zijn ('to be at the (V-inf)') and bezig zijn om te/met ( $V$-inf) ('to be busy to/with (V-inf)') or expressions containing posture verbs, such as zitten/lopen/staan/liggen te ( $V$-inf) ('to sit/walk/stand/lie to (V-inf)') (see Boogaart 1991, 1999; Ebert 2000; Lemmens 2005, etc.). Previous studies have put forward the hypothesis that the progressive aan het construction in Dutch is in the process of grammaticalization (von Stutterheim et al. 2009; van Ierland 2010; Flecken 2011a, 2011b; Behrens et al. 2013; Hilberink et al. in press). The process of grammaticalization of progressive aspect and the role of specific situation types will be explained below. 
3.1.1. Situation types. Studies of language production have looked at descriptions of different situation types (von Stutterheim et al. 2009) and the use of progressive aspect. The stimulus material covered different situation types presented as short, live-recorded video clips, of about six seconds in length. The stimuli include two situation types that are prominent in studies of progressive aspect, both in L1 and L2 acquisition, and cover so-called "activities" (situations involving ongoing leisure-time activities, described by 1-state verbs, cf. Klein 1994), as well as events typically expressed by accomplishment or achievement verbs. Although initially L2 learners were found to first mark verbs involving activities for progressive aspect, followed later by achievements, later cross-linguistic analyses showed a large degree of variation with findings that did not match initial predictions (see, for example, Shirai 2009). In contrast to these previous studies, and in order to eliminate confounding problems at a methodological level, use and acquisition of means to express aspect are examined in the present framework in relation to real world stimuli that depict activities or "achievements", taking into account relevant features of the specific L1 and L2 in the experimental design (von Stutterheim et al. 2009: 211). The first situation type, labeled "activities", show relatively homogeneous situations which last for a while and do not involve a salient change of state of the entities involved, e.g. a person surfing, playing the piano, or playing cards (see, for an example, Figure 1).

The second situation type consists of "situations which involve a salient 'qualitative' change of state with respect to an entity (an effected object, as when building a monument, knitting a scarf, making a paper airplane); the scenes all show progression toward a qualitatively characterized target state" (von Stutterheim et al. 2009: 211). "Causative actions" are thus situations in which an agent creates an object using a certain instrument (Figure 2). Even

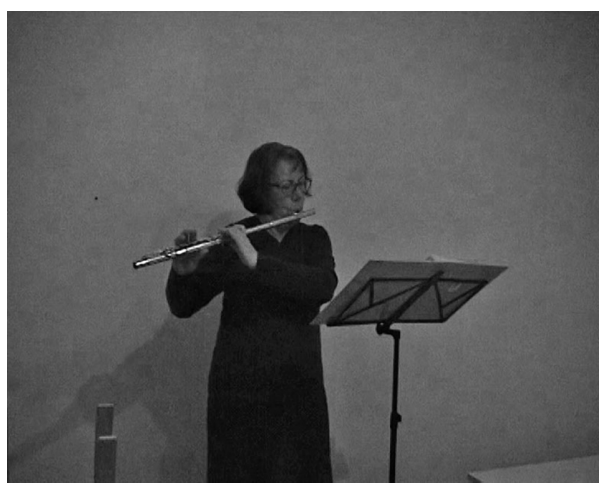

Figure 1. Example of an activity, 'playing the flute' 


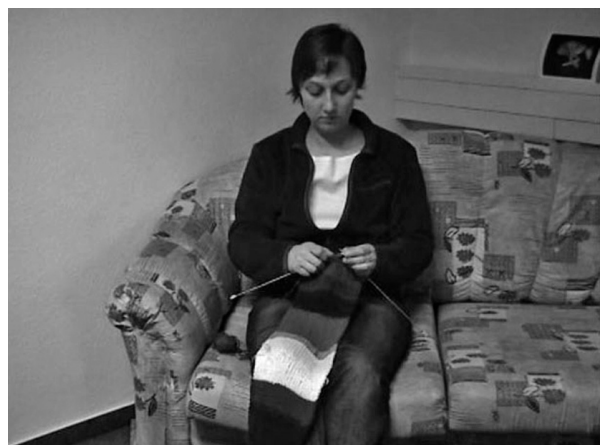

Figure 2. Example of a causative action, 'knitting a scarf'

though the video clips depict the ongoing phase of the event, this event type shows progressive changes of state leading to an inherent endpoint, characterized by the object being finished at some point in the future (e.g., a scarf will be completed at some point, which characterizes the inherent endpoint of the knitting event).

The third situation type relates to "motion events". Motion events are situations in which an entity, a person or vehicle, moves in a certain direction towards an endpoint (Figure 3).

It was found that these situation types attract use of progressive aspect to a different extent in Dutch: Activities and causative actions represent high attractors, whereas motion events represent a constraint on use of the aan het construction - progressive aspect is not used to describe this situation type (see in detail von Stutterheim et al. 2009; Behrens et al. 2013).

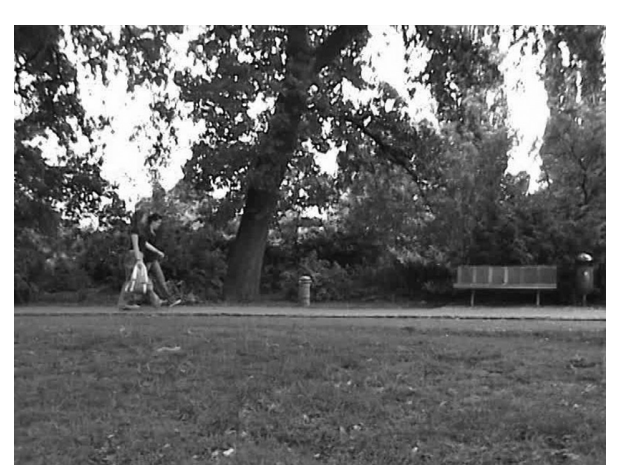

Figure 3. Example of a motion event, 'walking towards a bench/through the park' 
In Flecken (2011a) native Dutch speakers were asked to perform an acceptability judgment task, choosing between an aan het form and an unmarked verb form in descriptions of the above situation types. A similar set of findings was obtained: low acceptability for aan het forms in motion event descriptions (? twee vrouwen zijn naar een bankje aan het lopen 'two women are walking to a bench'). This apparent semantic constraint on motion events, which may be linked to the locative roots of the Dutch progressive aan het form, it being a locative preposition ('at'), was taken as evidence for a not yet completed process of grammaticalization of the form (Flecken 2011a; Carroll and Flecken 2012; Behrens et al. 2013). Similar constraints were observed for progressive aspect in Romance languages, using the same framework. Italian speakers used the available periphrastic construction (stare + gerund; the verb stare 'to stand' also has locative roots) with a low frequency to describe motion events, compared to the situations showing 'activities' as well progressive changes of state (causative actions), where use was high (Natale 2009).

\subsection{Event construal and progressive aspect in L2 Dutch}

Few studies have focused on progressive aspect and the construal of events in L2 Dutch. A previous analysis of event construal by early German-Dutch bilinguals (age of acquisition of both languages before the age of four, Flecken $2011 \mathrm{~b}$ ) attested overuse of the progressive aan het construction in the event descriptions, when compared to a monolingual Dutch baseline sample. Specifically, they displayed a higher frequency of use of progressives for causative actions, but also for motion events, for which monolingual Dutch speakers do not use the aan het construction. These findings were interpreted as showing how conceptual restrictions on use of the concept, related to its current stage of grammaticalization, are weaker for the bilinguals, compared to monolinguals. The other language of the bilinguals, German, shows different patterns: Forms functionally similar to the Dutch aan het construction are available, but they are hardly used by native speakers of German for any situation type. An analysis of event descriptions in German, produced by the same early bilingual population, showed that they did not use progressive forms - thus providing evidence of no influence from Dutch (Flecken 2010).

A study by van Ierland (2010) examined event descriptions by highly proficient late English-Dutch bilinguals. In this dataset, the late bilinguals used progressive aspect frequently, but not in all situation types to the same extent as Dutch native speakers. In particular, they displayed lower frequencies of use in descriptions of event type "activities". They evidenced a similar constraint on use for motion events, as found for Dutch monolingual speakers. In other words, even though they distinguished differences across situation types, use 
with "activities" did not reflect its status as a situation type with a high attractor effect in L1 Dutch. The late English-Dutch bilinguals did not transfer the L1 English pattern to Dutch (i.e., obligatory use of the progressive when asked to view ongoing, dynamic situations in video clips, and to tell what is happening). Van Ierland (2010) explains their lower use of aspect for "activities", compared to native speakers, as relating specifically to the type of verbs available in Dutch: Dutch has compact verbs relating to activities such as sports (voetballen, tennissen, biljarten), whereas English uses the verb 'to play', and then adds the specific activity, 'football/tennis'. The use of this type of verb for activities was transferred to Dutch, making the embedding of a progressive construction syntactically very complex, as, for example, the aan het form is usually embedded within the VP in native speaker event descriptions (voetbal aan het spelen, 'football at the play').

When comparing the two studies, we find use of progressive aspect in both samples of Dutch bilinguals, with the early German-Dutch bilinguals showing over-extension compared to the pattern and constraints in L1 Dutch. The late English-Dutch bilinguals recognize patterns of use where there are rigid constraints in Dutch, as with motion events, but proficiency at a lexical level may hinder use with 'activities' at this point, and not recognition of the status of this domain in Dutch for progressive aspect as such. Given the different source languages of the two groups of speakers, with the difference in age of acquisition, degree and length of exposure to Dutch as well as frequency of use, it is difficult at this point to draw conclusions on the acquisition of aspectual perspective-taking in L2 Dutch.

\section{The present study}

\subsection{Aims}

Given the previous findings summarized above, we will now give a more complete picture of the $\mathrm{L} 2$ acquisition of aspectual perspective taking in event construal in Dutch. Comparisons will be drawn regarding the age at which bilingual speakers acquired the two languages (i.e., early versus late bilinguals) with their differences in exposure to the L2, as well as the specifics of the language background of the speakers (i.e., aspect or non-aspect language as a native language). With regard to the role of the L1, the language selected in the present case, German, shows marginal use of forms that express progressive aspect, thereby contrasting with English. In giving these factors due weight, we expect the German L2 Dutch learners to have difficulties in uncovering target-like patterns of use, given the cross-linguistic contrast and the nature of the evidence for aspect marking in L1 Dutch. 
In addition to the acquisition of aspect, we investigate the interrelation between progressive aspect and specificity in event construal in an L2. The expression of the status of an event with regard to its specificity is crucial, as an event can involve a singular (e.g., birds are singing) and therefore 'specific' case, related to a specific reference time, or an unspecific event (birds sing), which is not temporally anchored and can be understood in generic terms. The relevance of specificity in the present study is given by the fact that progressive aspect anchors the event in time, in the here and now as in we are writing a paper, for example, and thus as a specific case. Other linguistic means can serve this function, when aspect is not used, or is not available, as in the case of German. We examine how specificity is marked in L2 Dutch, where an influence of L1 German may predominate. L1 German speakers verbalize more specific features of the situations depicted, given its status as a non-aspect language, and these patterns may transfer to the L2.

In sum, the analysis is based on descriptions of three different situation types (activities, causative actions, motion events), comparing advanced German L2 Dutch speakers (late bilinguals) to native speakers of both source and target language. Focus will be placed on the use of aspect and the means selected to anchor the event as a specific case, with a focus on descriptions of causative actions in the latter case.

\section{Method}

\subsection{Participants}

In the present study, data from two samples of L1 Dutch speakers and L1 German speakers (Flecken 2010) were re-analyzed. The dataset consists of L1 data from 19 Dutch students of Radboud University Nijmegen in the Netherlands ( $M_{\text {age }}=20.38$, age range: $18-27$ years). All L1 Dutch speakers were resident in the Netherlands. Furthermore, the dataset includes L1 data from 18 German students at the University of Heidelberg in Germany $\left(M_{\text {age }}=24.32\right.$, age range: 20-35 years), who were all resident in Germany. In the present study, we recorded data from a small sample $(N=9)$ very advanced L2 speakers of Dutch, with German as their native language. The L2 Dutch speakers were recruited at the Goethe Institute in Amsterdam in the Netherlands $\left(M_{\text {age }}=42.25\right.$, age range: $34-57$ years). All L2 participants were professionals, working and living in the Amsterdam area. They were all late bilinguals (i.e., they started acquiring Dutch in or after puberty) and had been living in the Netherlands for a number of years $(M=20.50$, range: $11-33$ years; see overview of demographic participant characteristics in Table 1 below). The details with respect to the participants' language background were obtained on the basis of exten- 
sive language background questionnaires, specifically designed for monolingual native speakers, and a separate one for late bilinguals/L2 users (inspired by existing questionnaires Gullberg and Indefrey 2003; Li et al. 2006; Marian et al. 2007).

The L2 users were classified as very advanced on the basis of, first of all, judgments by a native speaker of Dutch (with no knowledge of German) who had long conversations with them before the experimental session; second of all, an analysis of lexical or grammatical errors in the data elicited with this experiment (none could be identified), and, third of all, self-assessment of proficiency and language use. They indicated having daily exposure to Dutch, as well as daily use of Dutch, via the media, in the working environment (with co-workers), as well as in the family (7 participants indicated having a Dutchspeaking partner with whom they conversed in Dutch) and social contacts. They also assessed their percentage of use of Dutch and German on a daily basis, with Dutch between 60 and $95 \%$ of the day. In the self-assessments of proficiency, Dutch was assessed at nearly the same high level as German, in most cases.

\subsection{Stimuli}

The stimuli used were live-recorded, dynamic video clips showing dynamic situations (each lasting six seconds), namely activities, causative actions, and motion events. Each type consisted of several stimulus items (i.e., eight for activities, ten for causative actions, and ten for motion events, see full list of items in the Appendix). The data on use of progressives and marking of specificity were summed up and the mean frequencies of use per group of speakers of different languages were compared and analyzed.

The stimuli depicting causative actions all display an agent (man or woman, clearly visible) actively working on a clearly visible and identifiable object-inthe-making (e.g., a scarf, a paper airplane, a vase, etc.)

\subsection{Procedure}

Participants were shown a set of stimuli (65 in the studies of Flecken 2010; in the present study, the items of the three situation types, i.e., 28, were selected for analysis). Participants were instructed to tell what was happening in each video clip. Specifically, they were instructed as follows: Het is uw opgave om te vertellen wat er gebeurt in case of Dutch participants and Es ist ihre Aufgabe, $z u$ sagen was passiert ('it is your task to tell what is happening') in case of 
Table 1. Demographic participant characteristics

\begin{tabular}{ll}
\hline & Flecken (2010): L1 Dutch speakers \\
\hline $\mathrm{N}$ & 19 \\
Age range & $18-27$ years \\
Average age & 20.38 years \\
Country of residence & The Netherlands \\
Native language & Dutch \\
Second language(s) & English (intermediate proficiency) \\
\hline & Flecken (2010): L1 German speakers \\
\hline $\mathrm{N}$ & 18 \\
Age range & $20-35$ years \\
Average age & 24.32 years \\
Country of residence & Germany \\
Native language & German \\
Second language(s) & English (low-intermediate proficiency) \\
\hline & Present study: German L2 Dutch \\
& speakers \\
\hline $\mathrm{N}$ & 9 \\
Age range & $34-57$ years \\
Average age & 45.25 years \\
Country of birth & Germany \\
Country of residence & The Netherlands \\
Range of time of residence & $11-33$ years \\
Average time of residence in the Netherlands & 20.50 years \\
Native language & German \\
Second language(s) & Dutch (advanced proficiency), English \\
& (low proficiency) \\
\hline &
\end{tabular}

German participants. ${ }^{2}$ Furthermore, participants were instructed to start speaking as soon as they recognized what was happening and were thus allowed to speak while the video clip was shown. In between each video clip, there was a blank screen for eight seconds. Participants were explicitly instructed to focus on the situation itself. The experiment started with six practice trials. The experiment lasted 15 minutes and responses were recorded with a microphone and transcribed after the experiment. After the experiment, participants were asked to fill out a questionnaire.

2. It was shown that it made no difference whether the question was formulated in past, present, or progressive verb form (van Ierland 2010). 


\section{Results}

In order to obtain a general overview of the use of progressive aspect, an overall analysis of all event descriptions was performed. In addition, the frequency of use of progressives was analyzed per situation type. Utterances were characterized as containing a progressive verb form, when they entailed the aan het construction, a posture verb construction, or the more lexical bezig om te/met phrase. A further qualitative analysis focuses on the use of specific types of progressive markers. For the German data, event descriptions were characterized as including a progressive aspectual marker, when they contained the am or beim construction (am/beim Verbal-noun sein), or the construction dabei sein $z u+\mathrm{V}$-inf.

First of all, the data of the L1 Dutch and L1 German participants were compared. Second of all, the German L2 Dutch data were compared to L1 Dutch data, to explicitly compare performance of the $\mathrm{L} 2$ users in the target language to performance by native speakers of the target language. All comparisons of use of progressive aspect were made by means of ANOVAs on participant $(F 1)$ and item $(F 2)$ means. All means displayed are participant means; the figures show frequencies of use of progressive markers for each speaker group, as percentages of the total number of utterances produced. The analyses on specificity are qualitative in nature, since we are dealing with categorical variables, with low frequencies in each category.

The analysis on specificity was carried out for 'causative actions' specifically, as previous studies show a high frequency of use of progressives in L1 Dutch, but not in L1 German. The causative action stimuli show a change of state of an identifiable object and this is typically mentioned as argument of the main verb (moulding a vase, drawing a tree). In the stimuli depicting activities there is no change of state of the object(s) involved (e.g., playing football, surfing, playing tennis) and they need not be mentioned to the same extent as objects in causative actions. Coding focuses on (1) specificity in reference to the agent: Is the agent described by means of (a) an unspecific noun phrase (e.g., somebody or a person) (category 'N.unspecific'), (b) a noun phrase (e.g., a man or $a$ woman) (category ' $\mathrm{N}$ '), or (c) a more complex noun phrase, including an adjective or prepositional adjunct (e.g., a young man, a blond woman, a man with glasses or a man with a red sweater) (category 'complex NP') (2) specificity in reference to the action, through extra-verbal means, such as (a) mention of the object being acted upon, yes or no (a person is knitting a scarf, vs. a person is knitting), (b) mention of the instrument with which the action is performed (e.g., drawing a tree with a pencil), (c) mention of the location at which the event takes place (e.g., knitting a scarf in a chair), or (d) highlighting specific features of the objects involved (e.g., knitting a blue and white scarf or beading a necklace offake pearls). 


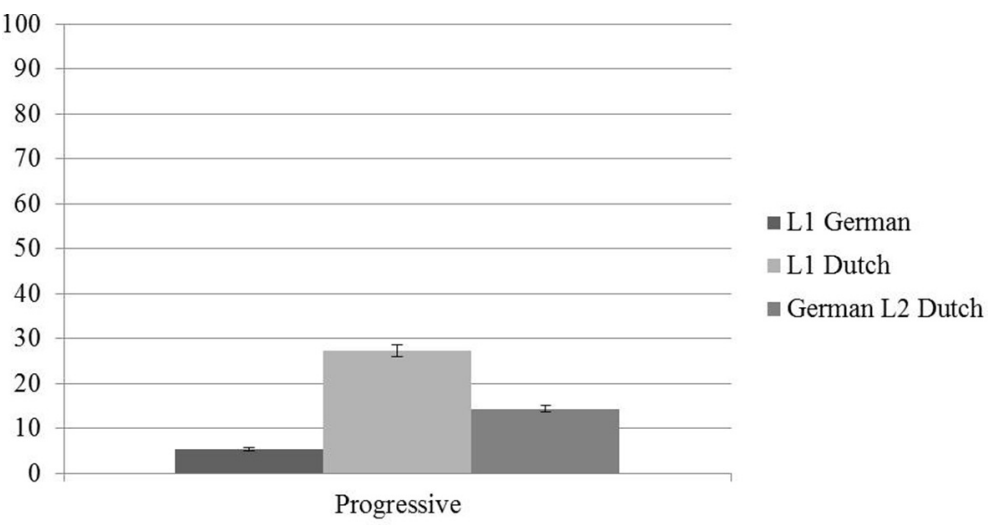

Figure 4. Use of progressive verb forms (\% of total number of utterances. Error bars indicate $95 \%$ confidence intervals)

Table 2. Use of progressive forms

\begin{tabular}{llccc}
\hline Language & & Progressive & No progressive & Total \\
\hline L1 German & Frequency & 25 & 479 & 504 \\
& $\%$ & 4.96 & 95.04 & 100 \\
L1 Dutch & Frequency & 145 & 387 & 532 \\
& $\%$ & 27.26 & 72.74 & 100 \\
\multirow{4}{*}{ L2 Dutch } & Frequency & 32 & 220 & 252 \\
& $\%$ & 12.69 & 87.30 & 100 \\
\hline
\end{tabular}

\subsection{Use of progressive verb forms}

6.1.1. All utterances. Use of progressive forms differed significantly across the three groups of speakers $(F 1(2,46)=17.85, p<.001 ; F 2(2,84)=18.42$, $p<.001)$. Post-hoc tests (Bonferroni corrected) show that the L1 German speakers $(M=1.39, S D=2.55)$ used progressive forms less than the L1 Dutch speakers $(M=7.63, S D=3.90 ; p<.001)$. The L2 Dutch speakers $(M=3.22$, $S D=2.86)$ used progressive markers with a lower frequency than the L1 Dutch speakers ( $p<.05$; see Figure 4 and Table 2 below).

\subsection{Use of progressive verb forms by situation type}

Figure 5 and Table 3 show the use of progressive forms for each situation type, for the three groups of speakers. 


\section{Gercoline van Beek, Monique Flecken and Marianne Starren}

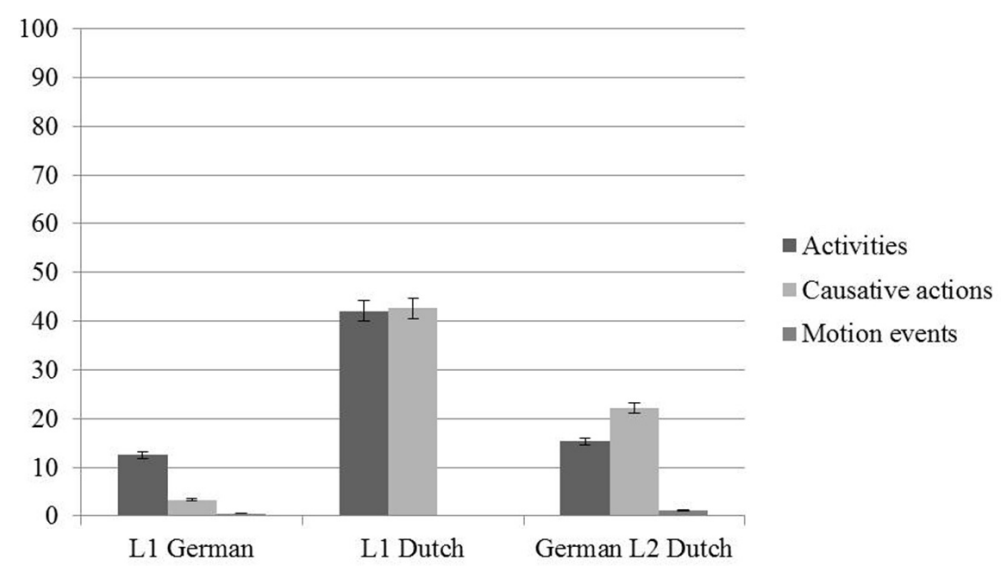

Figure 5. Use of progressive markers per situation type (\% of total number of utterances)

Table 3. Use of progressives per situation type

\begin{tabular}{llccc}
\hline Language & & Progressive & No progressive & Total \\
\hline L1 German & Frequency & $18 / 144$ & $6 / 180$ & $1 / 180$ \\
& $\%$ & 12.50 & 3.33 & 0.56 \\
L1 Dutch & Frequency & $64 / 152$ & $81 / 190$ & $0 / 190$ \\
& $\%$ & 42.11 & 42.63 & 0 \\
L2 Dutch & Frequency & $11 / 72$ & $20 / 90$ & $1 / 90$ \\
& $\%$ & 15.28 & 22.22 & 1.11 \\
\hline
\end{tabular}

ANOVAs were conducted on frequencies of use of progressive markers, including the factors language and situation type. There was a significant main effect of language $(F 1(2,138)=29.92, p<.001 ; F 2(2,84)=47.74, p<.001)$, as well as a significant main effect of situation type $(F 1(2,138)=27.42, p<$ $.001 ; F 2(2,84)=35.21, p<.001)$. There was also a significant interaction between language and situation type $(F 1(4,138)=9.71, p<.001 ; F 2(4,84)=$ $13.97, p<.001)$. The L1 German speakers used progressive markers more frequently in descriptions of activities, whereas the L1 and L2 Dutch speakers used progressive forms more frequently in descriptions of causative actions. Post-hoc tests for situation types (Bonferroni corrected) show that motion event descriptions were marked with progressive aspect significantly less than the other two situation types (activities: $M=1.83$; causative actions: $M=2.234$; motion events: $M=0.02, p<.001$ ). Below, separate comparisons per situation type are listed, as well as the types of progressive markers used, for each situation type. 
Table 4. Types of progressives used in descriptions of "activities"

\begin{tabular}{|c|c|c|c|c|c|c|}
\hline \multirow{2}{*}{$\begin{array}{l}\text { Language } \\
\text { L1 Dutch }\end{array}$} & \multirow[b]{2}{*}{$\begin{array}{l}\text { Frequency } \\
\%\end{array}$} & \multicolumn{2}{|c|}{$\begin{array}{l}\text { Progressive use } \\
\text { (all types) }\end{array}$} & \multirow{2}{*}{$\begin{array}{c}\begin{array}{c}\text { Aan het } \\
\text { construction }\end{array} \\
55\end{array}$} & \multirow{2}{*}{$\begin{array}{c}\text { Posture verbs/ } \\
\text { bezig }\end{array}$} & \\
\hline & & $\begin{array}{c}64 \\
42,11\end{array}$ & $\begin{array}{l}152 \\
100\end{array}$ & & & \\
\hline L2 Dutch & $\begin{array}{l}\text { Frequency } \\
\%\end{array}$ & $\begin{array}{c}11 \\
15,28\end{array}$ & $\begin{array}{c}72 \\
100\end{array}$ & 5 & 6 & \\
\hline Language & & $\begin{array}{l}\text { Progre } \\
\text { (all typ }\end{array}$ & use & $\begin{array}{c}\text { Beim } \\
\text { construction }\end{array}$ & $\begin{array}{c}A m \\
\text { construction }\end{array}$ & $\begin{array}{c}\text { Dabei sein zu } \\
\text { construction }\end{array}$ \\
\hline L1 German & $\begin{array}{l}\text { Frequency } \\
\%\end{array}$ & $\begin{array}{c}18 \\
12.40\end{array}$ & $\begin{array}{l}144 \\
100\end{array}$ & 18 & 0 & 0 \\
\hline
\end{tabular}

6.2.1. Activities. For descriptions of activities, there was an effect of language $(F 1(2,46)=7.85, p<.05 ; F 2(2,24)=21.60, p<.001)$. Post-hoc tests with Bonferroni correction show that the L1 German speakers $(M=1.00$, $S D=1,81)$ used progressive markers less than the L1 Dutch speakers $(M=$ $3.26, S D=2.08 ; p<.05)$. The L2 Dutch speakers $(M=1.22, S D=1.30)$ also displayed a lower frequency than the native Dutch speakers $(p<.05)$.

Table 4 shows the types of progressive markers used by all participants for activities. The numbers display a predominance of the aan het construction in the L1 Dutch group, and a low frequency of use of aan het in the L2 Dutch group.

6.2.2. Causative actions. In descriptions of causative actions, use of progressive forms differed significantly across the three groups $(F 1(2,46)=27.08$, $p<.001 ; F 2(2,30)=26.02, p<.001)$. Post-hoc tests with Bonferroni correction show that the $\mathrm{L} 1 \mathrm{German}$ speakers $(M=0.33, S D=0.69)$ used progressive markers less than the L1 Dutch speakers $(M=4.37, S D=2.17 ; p<.001)$. The L2 Dutch speakers $(M=2.00, S D=1.87)$ used progressive aspect less than the L1 Dutch group $(p<.05)$. Table 5 below lists the types of progressive markers used.

Table 5 again shows dominant use of the aan het construction for the L1 Dutch group. The L2 Dutch speakers show a relatively high frequency of use of posture verb constructions, but overall numbers are quite low.

6.2.3. Motion events. For motion events, use of progressive forms did not differ significantly across the three groups of speakers $(F 1(2,46)=0.77, p=$ .469 , n.s.; $F 2(2,30)=1.00, p=.381$, n.s.) as use amounts to zero or one in all groups. 
Table 5. Types of progressives used in descriptions of "causative actions"

\begin{tabular}{|c|c|c|c|c|c|c|}
\hline \multirow{2}{*}{$\begin{array}{l}\text { Language } \\
\text { L1 Dutch }\end{array}$} & \multirow[b]{2}{*}{$\begin{array}{l}\text { Frequency } \\
\%\end{array}$} & \multicolumn{2}{|c|}{$\begin{array}{l}\text { Progressive use } \\
\text { (all types) }\end{array}$} & \multirow{2}{*}{$\begin{array}{c}\begin{array}{c}\text { Aan het } \\
\text { construction }\end{array} \\
66\end{array}$} & \multirow{2}{*}{$\begin{array}{c}\begin{array}{c}\text { Posture verbs/ } \\
\text { bezig }\end{array} \\
15\end{array}$} & \\
\hline & & $\begin{array}{c}81 \\
4263\end{array}$ & $\begin{array}{l}190 \\
100\end{array}$ & & & \\
\hline L2 Dutch & $\begin{array}{l}\text { Frequency } \\
\%\end{array}$ & $\begin{array}{c}20 \\
22.22\end{array}$ & $\begin{array}{c}90 \\
100\end{array}$ & 6 & 14 & \\
\hline Language & & $\begin{array}{l}\text { Progre } \\
\text { (all typ }\end{array}$ & use & $\begin{array}{c}\text { Beim } \\
\text { construction }\end{array}$ & $\begin{array}{c}A m \\
\text { construction }\end{array}$ & $\begin{array}{c}\text { Dabei sein } z u \\
\text { construction }\end{array}$ \\
\hline L1 German & $\begin{array}{l}\text { Frequency } \\
\%\end{array}$ & $\begin{array}{c}6 \\
3.33\end{array}$ & $\begin{array}{l}180 \\
100\end{array}$ & 5 & 0 & 1 \\
\hline
\end{tabular}

\subsection{Level of specificity in descriptions of causative actions}

6.3.1. Level of specificity in reference to the agent. Table 6 and Figure 6 present the frequency of occurrence of the three coding categories for agent descriptions, for event type causative actions. As the frequencies in each category are low, we will mainly provide qualitative analyses of the patterns obtained.

The numbers show a high frequency of use of unspecific noun phrases (somebody, a person) in the L1 Dutch group, when compared to the L1 German and L2 Dutch group. In the L1 German group, we find a higher frequency of complex noun phrases, providing specific details on the agent. A similar pattern is visible in the L2 Dutch group. However, due to the lack of a quantitative analysis, we can only rate these findings as tentative.

Table 6. Level of specificity in reference to the agent

\begin{tabular}{llcccc}
\hline Language & & \multicolumn{3}{c}{ Agent: Level of specificity } \\
\cline { 3 - 6 } & & Unspecific noun & Noun & Complex NP & Total \\
\hline L1 German & Frequency & 24 & 134 & 22 & 180 \\
& $\%$ & 13.33 & 74.44 & 12.22 & 100 \\
L1 Dutch & Frequency & 53 & 134 & 3 & 190 \\
& $\%$ & 27.89 & 70.53 & 1.58 & 100 \\
L2 Dutch & Frequency & 8 & 70 & 12 & 90 \\
& $\%$ & 8.89 & 77.78 & 13.33 & 100 \\
\hline
\end{tabular}




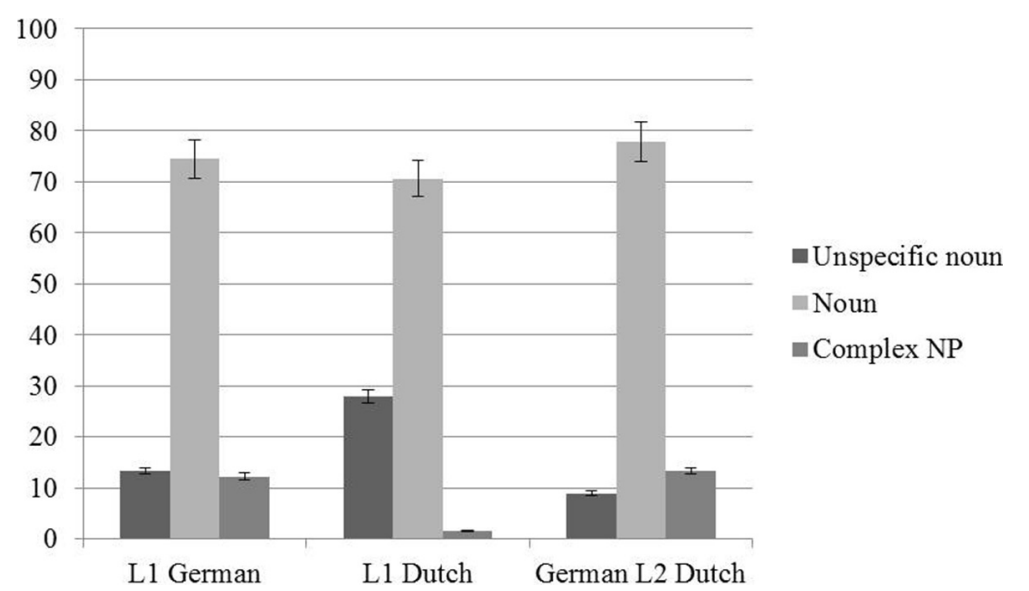

Figure 6. Level of specificity in reference to the agent (\% of total number of utterances)

\subsubsection{Level of specificity in reference to the action.}

(a) Mentioning of object. Table 7 and Figure 7 give the frequency of utterances in which the depicted object (i.e., the scarf being knit, the vase the potter is moulding, the tree someone is drawing) is overtly mentioned in the description of the event.

An ANOVA based comparison shows that the extent to which the object was encoded in the descriptions differed significantly across the three groups of speakers $(F 1(2,46)=10.29, p<.001 ; F 2(2,30)=1.52, p=0.24$, n.s. $)$, but only in the F1 analysis (on participant means). Post-hoc tests (Bonferroni corrected) show that the L2 Dutch speakers $(M=7.00, S D=1.23)$ did not differ from the L1 Dutch speakers $(M=7.32, S D=1.06)$, but both groups encoded the object in fewer cases than the L1 German speakers $(M=8.78$, $S D=1.22 ; p<.001)$

Table 7. Object encoding

\begin{tabular}{llccc}
\hline Language & & Object encoding & No encoding of object & Total \\
\hline L1 German & Frequency & 159 & 21 & 180 \\
& $\%$ & 88.33 & 11.67 & 100 \\
L1 Dutch & Frequency & 139 & 51 & 190 \\
& $\%$ & 73.16 & 26.84 & 100 \\
\multirow{2}{*}{ L2 Dutch } & Frequency & 66 & 24 & 90 \\
& $\%$ & 73.33 & 26.67 & 100 \\
\hline
\end{tabular}


218 Gercoline van Beek, Monique Flecken and Marianne Starren

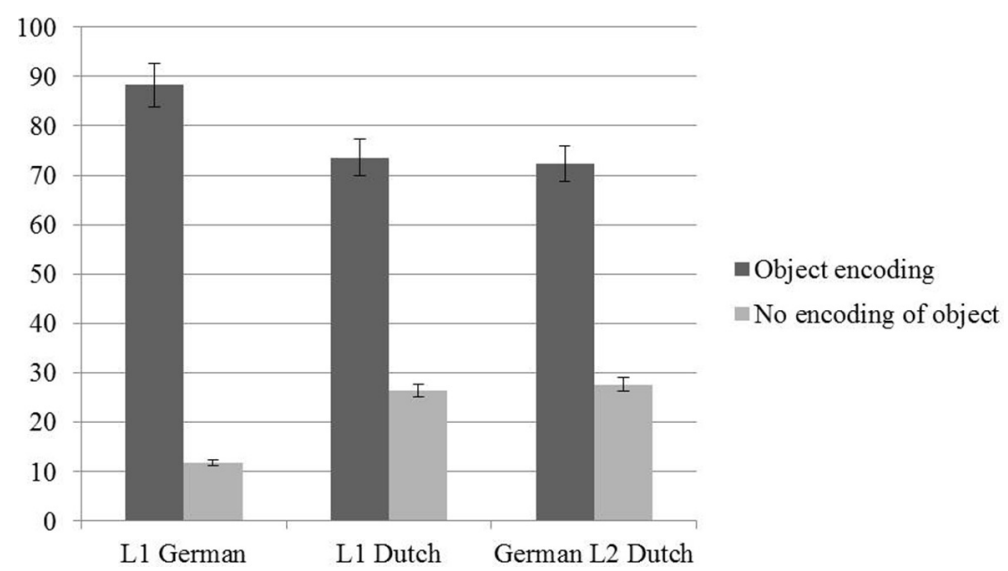

Figure 7. Object encoding (\% of total number of utterances)

(b) Action-specific adjuncts. Table 8 and Figure 8 show how frequently speakers in the three groups resort to adjuncts detailing specific aspects of the action (for example, mentioning of the instrument, the location of the event, or details with respect to the object).

The extent to which action-specific adjuncts were encoded did not differ significantly across the three groups $(F 1(2,46)=2.85, p=.069$, n.s.; $F 2(2,30)=$ $2.02, p=.153)$. The raw frequencies above merely point to a trend in the direction of a higher relative frequency of use of action adjuncts by the L2 Dutch speakers.

Table 8. Action-specific adjuncts

\begin{tabular}{|c|c|c|c|c|c|c|c|}
\hline \multirow[t]{2}{*}{ Language } & & \multicolumn{2}{|c|}{ Use of adjuncts } & \multicolumn{3}{|c|}{ Type } & \multirow[t]{2}{*}{ Total } \\
\hline & & $\begin{array}{c}\text { No } \\
\text { adjuncts }\end{array}$ & $\begin{array}{l}\text { Action- } \\
\text { specific } \\
\text { adjuncts }\end{array}$ & Instrument & $\begin{array}{l}\text { Adjunct } \\
\text { location }\end{array}$ & Object & \\
\hline \multirow{2}{*}{ L1 German } & Frequency & 115 & 65 & 36 & 17 & 12 & 180 \\
\hline & $\%$ & 63.89 & 36.11 & 20.00 & 9.44 & 6.67 & 100 \\
\hline \multirow[t]{2}{*}{ L1 Dutch } & Frequency & 118 & 72 & 50 & 4 & 18 & 190 \\
\hline & $\%$ & 62.11 & 37.89 & 26.32 & 2.11 & 9.47 & 100 \\
\hline \multirow[t]{2}{*}{ L2 Dutch } & Frequency & 40 & 50 & 24 & 24 & 2 & 90 \\
\hline & $\%$ & 44.44 & 55.56 & 26.67 & 26.67 & 2.22 & 100 \\
\hline
\end{tabular}




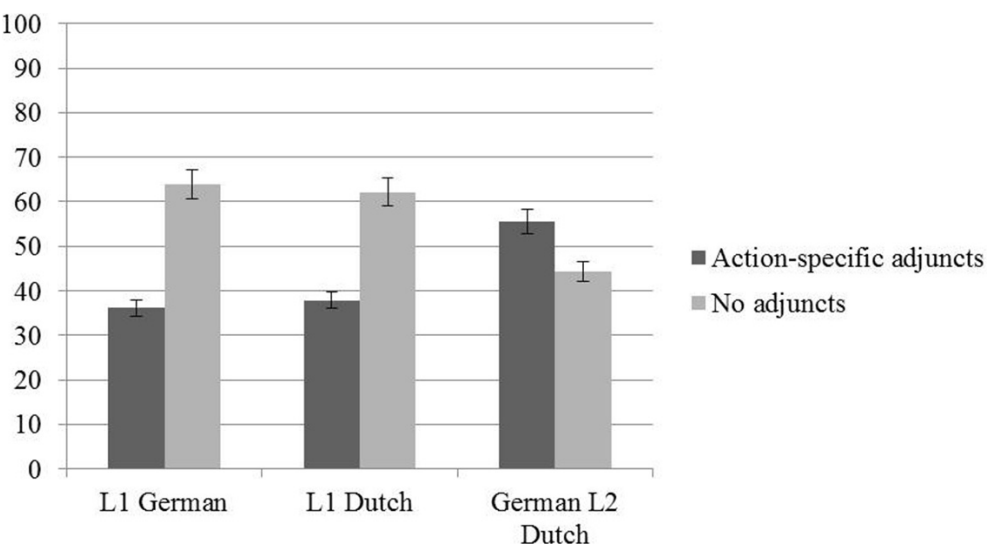

Figure 8. Encoding of action-specific adjuncts (\% of total number of utterances)

\subsection{Summary of findings}

Results on use of markers of progressive aspect confirm previous findings, showing that the L1 German speakers do not use progressive markers and the L1 Dutch speakers show clear preferences and constraints on use of progressive aspect: The Dutch speakers use progressive aspect (mainly the aan het construction) to describe causative actions and activities to an equal extent, but not motion events. The L2 Dutch speakers use progressive forms significantly less frequently than the L1 Dutch speakers, both for causative actions and activities. However, they encode aspect slightly more frequently in descriptions of causative actions compared to activities. As in L1 Dutch, aspect is not used with motion events. An inspection of types of progressive markers used shows a low number of aan het constructions for the L2 Dutch speakers.

With respect to the encoding of specificity on the agent or the action through non-verbal means in the causative action descriptions, numbers indicate that the L1 Dutch speakers use unspecific noun phrases to a higher extent than speakers in the two other groups. The latter two groups display a higher frequency of use of complex noun phrases, elaborating specific visual features of the agent displayed in the stimuli (e.g., hair colour, age, or clothing). Furthermore, speakers of German mention the object in a causative action stimulus more frequently than both groups of Dutch speakers. With respect to expressing specific details on the action outside the verb through adjuncts and adjectival phrases, we find a comparable pattern in the three groups, with percentages indicating a slightly higher frequency in the L2 Dutch group. They express more details with respect to specific features of the action, such as the location at 
which the action takes place (in a chair, on a sofa, at a table, etc.). In summary, we find that the L2 Dutch speakers are slightly more specific in their references to agents, compared to the L1 Dutch speakers, resembling their native language pattern. With respect to the encoding of objects, the L2 Dutch speakers resemble the target-like pattern. The data show a tendency for the L2 Dutch speakers to express specificity of the action through lexical means (i.e., adjuncts), rather than via grammatical means (progressive aspect), as was done by the L1 Dutch speakers - the difference in adjunct encoding was not significant however.

\section{Discussion}

Starting with the frequency and type of construction used to express aspect, we found that the German L2 Dutch speakers used progressive forms less frequently than the L1 Dutch speakers. They did not use the Dutch aan het construction to the same extent as native speakers - a construction that resembles means in their native language, in which similar forms are available ( $\mathrm{am}$ construction), but are not used. In L1 Dutch, progressive aspect is used highly frequently for specific situation types, but use is constrained for motion events. This pattern is also found in the L2 Dutch speakers, with a slight preference for using progressive forms in descriptions of causative actions compared to activities. The L2 Dutch speakers thus adhere to the target language constraint on use of aspect in motion events, but overall they do not show the same high frequency of use for situation types that "attract" progressive forms in native Dutch. Even very advanced L2 users thus do not fully reflect target language preferences in aspectual perspective taking. This finding may be explained in several ways: Use of aspect in L1 German occurs mainly in descriptions of activities; the fact that the L2 Dutch speakers also use progressive constructions for causative actions indicates that the learners do not simply transfer preferences from their L1. With regard to the question of overall frequency of use, aspect marking is observed in Dutch at a rate of less than thirty percent of all relevant utterances, and in this context it should be noted that in Dutch, descriptions without progressive aspect are perfectly grammatical as well. If this can be used as an indicator for the learner's exposure, it may contribute to the relatively low frequency in an $\mathrm{L} 2$. With regard to the situational properties that attract use of aspect, the L2 also reflects the L1 German pattern (apart from a slight increase in frequency for causative events) along with the domain in which use is highly constrained. This shows that they have inferred that conceptual, situational properties play a role in determining principles of use.

An interesting comparison can be made with the data in Flecken (2011b) who looked at event construal by early German-Dutch bilinguals. In this study, using the same stimuli and experimental procedure, the early bilinguals were 
found to overuse the progressive aan het construction in Dutch; this pattern was found for the situation types in which monolingual Dutch speakers also use the concept, causative actions and activities, but use was also extended to the domain of motion events, a domain in which use is highly constrained. The early bilingual sample, as well as the L2 Dutch speakers (late bilinguals) in the present study, were highly proficient and did not make any grammatical or lexical errors in their event descriptions. We thus find two distinct patterns in two different samples of Dutch bilinguals, with the same language combination (German-Dutch): a much lower frequency of use of progressive aspect in the late bilinguals for the main situation types, and a pattern of overuse in the early bilinguals, with an extension to a situational domain that is a constraint on use for monolingual native speakers. These different patterns may show evidence for different acquisitional paths and a potential effect of different degrees of exposure to a first and second language, as well as the nature of the input. Leaving all other factors aside, the language learning situation for early and late bilinguals are very different with respect to variables playing a crucial role in the acquisition of "thinking for speaking" patterns (see Athanasopoulos 2011; Bassetti and Cook 2011), namely age of acquisition (early versus late), length of residence in the L2 speaking community (in case of the early German-Dutch bilingual sample: Nearly all participants resided in the Netherlands since birth; average length of residence in the present sample of late German-Dutch bilinguals: 20.50 years), and degree, intensity, and length of exposure to the L2 (Dutch). Previous studies show a benefit in obtaining a high level of proficiency for early bilinguals, when compared to late bilinguals, relating to all or a combination of some of the above mentioned factors. In the present case, we may see this as well: The late bilinguals (the present sample of German L2 Dutch speakers) have begun to acquire Dutch after their German system has been fully developed - this means that they have become habituated to speaking about events without taking an explicit ongoing perspective, and to talking about events with a higher degree of specificity through adjuncts and adjectives. As mentioned above, progressive aspect does not only entail acquisition of a form, but it entails learning to take a specific perspective on an event, with relevant implications for the way in which information is organized. The present findings indicate that this is indeed a difficult task for a late second language learner. The data in Flecken (2011b) indicate that the acquisition of principles of use of the Dutch progressive marker is difficult, even given longer, more, and earlier in life exposure to event construal patterns - the early bilinguals have acquired use of the form, but the subtle principles, and specifically constraints on use, seem to be less deeply entrenched, when compared to monolingual native speakers of Dutch.

Findings with respect to marking specificity indicate that the L2 Dutch speakers encode more specific information on the agent of the action, similar to the 
L1 German speakers (however, due to the lack of quantitative analyses, the data are only tentative). In particular, the L1 Dutch speakers show a lower level of specificity in references to agents. The pattern found in the L2 Dutch group may thus reflect subtle transfer effects. With respect to specific details on the action as expressed lexically (i.e., the instrument with which an action is carried out or the location at which it takes place), we see a similar degree of specificity in the three groups. As the numbers show a higher frequency for the L2 Dutch group, compared to either L1 German or L1 Dutch, this could be viewed as a potential process of 'restructuring' of perspective taking; a targetlike high degree of attention to the action. Given the fact that they are likely to have encountered action descriptions marked by progressive aspect in the Dutch input and their own use of aspect in causative actions, the findings could be interpreted as follows: The L2 Dutch speakers may have recognized that the action of an event is highly relevant in Dutch, with respect to specificity. They may have realized that attending and referring to specific action phases by means of progressive aspect is the preferred way to encode specificity of an event in Dutch. In other words, they may have realized that progressive aspect encodes not only that a situation is ongoing, but specifically, that a specific situation is ongoing, anchored in the here and now. The pattern found, though findings are only tentative, may show that the L2 Dutch speakers encode the event's status as specific on the basis of action features, but they do not yet do so systematically by means of progressive aspect.

Looking at a potential influence of the learners' L1, a comparison with English L2 Dutch speakers (van Ierland 2010) is highly relevant. English is a language with a highly grammaticalized marker of progressive aspect. In studies with a similar set up and stimulus material, use of progressive aspect is obligatory in English (marking ongoing events in the present), in contrast to Dutch. The Dutch progressive form is not formally similar to the English form, in contrast to the am construction in German, so the question is whether English L2 users of Dutch apply the Dutch aan het construction, and if so, to what situation types. Van Ierland (2010) found a high frequency of use of progressive aspect (aan het): The English L2 Dutch speakers did not use progressive aspect in descriptions of motion events, resembling the native Dutch constraint, as with the current sample of L2 Dutch speakers. Similarly, both the German L2 Dutch and English L2 Dutch speakers used aspect more frequently in situations showing progressive changes of state (causative actions) when compared to activities. This means that both samples of late bilinguals, with a different language background, display aspectual perspective taking reflecting patterns found for L1 Dutch. The two learner groups differ with regard to overall frequency of use of progressive aspectual constructions. Use is lower for the German L2 Dutch group in the present study. The English L2 Dutch speakers investigated in van Ierland (2010) show specific difficulties at the construc- 
tional level (morpho-syntax) with respect to 'activities'; this pattern was not found in the present study. These different usage patterns, i.e., the pattern of "underuse" in the German L2 Dutch speakers and the high frequency of use in the English L2 Dutch speakers, may indicate at least partial transfer patterns. The fact that use of aspect is almost entirely absent in German, and this pattern is also frequent in Dutch, may have caused a stronger adherence to source language frequencies of use in the German L2 Dutch speakers. To some extent, the German and the Dutch pattern converge - this actually makes it impossible to determine whether the German L2 Dutch speakers actually transfer thinking for speaking patterns from their L1, or whether they are led to use the pattern in the Dutch input that is most systematic, and less complex (i.e., use of non progressive verb forms is not dependent on the specific situation being described). Apart from the relevant differences in frequency and overuse, the bilinguals have recognized the domains that both license and constrain use of progressive aspect in Dutch.

\section{General conclusions}

The findings of the present study provide more evidence for the fact that speakers of different languages conceptualize situations in different ways (Boroditsky 2001; Carroll et al. 2004; von Stutterheim et al. 2009; van Ierland 2010; Flecken 2011 b, etc.). We also support the position that grammatical aspect guides the selection of a specific perspective on a situation or event, given its consequences for information organization, at sentence and discourse level (von Stutterheim et al. 2012). For Dutch specifically, we find differences in the use of the progressive aan het construction across situation types, and these patterns of use differ across L1 and very advanced L2 speakers of Dutch. Findings from the present sample of L2 Dutch speakers indicate subtle influences of the native language, with respect to information selection and different means to encode specificity - through focusing more on the agent or the action in an event, and by using grammatical means, progressive aspect, or lexical means, phrases relating to agent or action details. The present study supports previous studies showing difficulty in acquiring target language patterns in habitual perspective taking on events, even given high proficiency levels and extensive exposure to a language.

Radboud University Nijmegen 


\section{Appendix: List of stimuli}

\begin{tabular}{lll}
\hline Activities & Causative actions & Motion events \\
\hline $\begin{array}{l}\text { A woman playing the } \\
\text { piano }\end{array}$ & A woman beading a & Two nuns walking \\
Two men playing & A woman building a & towards a convent \\
billiards & A car driving past a \\
A man surfing in the & A man folding a paper & cornfield to a village \\
ocean & airplane & village \\
A woman playing the & A potter moulding a & A woman leaving a \\
flute & vase & supermarket \\
Two women playing & A painter painting a & A woman walking \\
cards & picture & towards a barrier \\
Men playing indoor & A man drawing a tree & A man climbing a \\
football & & ladder to a balcony \\
Men playing tennis & A woman decorating a & A man crossing a street \\
(outdoor) & cake with cream & to a car \\
A man exercising with & A woman building a & A girl on a horse riding \\
a dumbbell & tower with blocks & towards a gate \\
& A woman making a & A mother and child \\
& play dough man & walking towards a slide \\
& A woman knitting a & A car driving towards a \\
& scarf & petrol station \\
\hline
\end{tabular}

\section{References}

Athanasopoulos, Panos. 2011. Cognitive restructuring in bilingualism. In Aneta Pavlenko (ed.), Thinking and speaking in two languages, 29-65. Clevedon: Multilingual matters.

Bassetti, Benedetta \& Vivian Cook. 2011. Relating language and cognition: The second language user. In Vivian Cook \& Benedetta Bassetti (eds.), Language and bilingual cognition, 143-190. New York: Psychology Press.

Behrens, Bergljot, Monique Flecken \& Mary Carroll. 2013. Progressive attraction: On the use and grammaticalization of progressive aspect in Dutch, Norwegian and German. Journal of Germanic linguistics 25.

Benazzo, Sandra, Monique Flecken \& Efsathia Soroli. 2012. Typological perspectives on second language acquisition. In Sandra Benazzo, Monique Flecken \& Efstathia Soroli (eds.), Typological perspectives on second language acquisition: 'Thinking for Speaking' in L2, Language, interaction, and acquisition (special issue) 3(2), 163-172.

Berman, Ruth \& Dan I. Slobin. 1994. Relating events in narrative: A crosslinguistic developmental study. Hillsdale, NJ: Lawrence Erlbaum.

Boogaart, Ronny. 1991. Progressive aspect in Dutch. In Frank Drijkoningen \& Ana van Kemenade (eds.), Linguistics in the Netherlands, 1-9. Amsterdam: Benjamins.

Boogaart, Ronny. 1999. Aspect and temporal ordering: A contrastive analysis of Dutch and English. Amsterdam: Vrije Universiteit Amsterdam dissertation. 
Boroditsky, Lera. 2001. Does language shape thought? English and Mandarin speakers' conceptions of time. Cognitive psychology 43(1). 1-22.

Brown, Amanda \& Marianne Gullberg. 2008. Bidirectional crosslinguistic influence in L1-L2 encoding of manner in speech and gesture: A study of Japanese speakers of English. Studies in second language acquisition 30(2). 225-251.

Bylund, Emanuel. 2009. Effects of age of L2 acquisition on L1 event conceptualization patterns. Bilingualism: Language and cognition 12(3). 305-322.

Bylund, Emanuel. 2011. Language-specific patterns in event conceptualization: Insights from bilingualism. In Aneta Pavlenko (ed.), Thinking and speaking in two languages, 108-142. Clevedon: Multilingual matters.

Bylund, Emanuel \& Scott Jarvis. 2011. L2 effects on L1 event conceptualization. Bilingualism: Language and cognition 14(1). 47-59.

Cadierno, Teresa \& Lucas Ruiz. 2006. Motion events in Spanish L2 acquisition. Annual review of cognitive linguistics 4(1). 183-216.

Carroll, Mary, Christiane von Stutterheim \& Ralf Nüse 2004. The language and thought debate: A psycholinguistic approach. In Christopher Habel \& Thomas Pechmann (eds.), Approaches to language production, 183-218. Berlin: Mouton de Gruyter.

Carroll, Mary \& Christiane von Stutterheim. 2011. Event representation, time event relations, and clause structure: A crosslinguistic study of English and German. In Jürgen Bohnemeyer \& Eric Pederson (eds.), Event representation in language and cognition, 68-82. Cambridge: Cambridge University Press.

Carroll, Mary \& Monique Flecken. 2012. Language production under time pressure: Insights into grammaticalisation of aspect (Dutch, Italian) and language processing in bilinguals (DutchGerman). In Bernt Ahrenholz (ed.), Einblicke in die Zweitspracherwerbsforschung und ihre methodischen Verfahren, 49-75. Berlin: Mouton de Gruyter.

Comrie, Bernard. 1976. Aspect. Cambridge: Cambridge University Press

Cook, Vivian. 2002. Portraits of the L2 user. Clevedon: Multilingual matters.

Dahl, Östen. 1985. Tense and aspect systems. Oxford: Blackwell.

Ebert, Karen. 2000. Progressive markers in Germanic languages. In Östen Dahl (ed.), Tense and aspect in the languages of Europe, 605-653. Berlin: Mouton de Gruyter.

Flecken, Monique. 2010. Event conceptualization in language production of early bilinguals. Utrecht: Igitur (LOT dissertation series 256).

Flecken, Monique. 2011a. What native speaker judgements tell us about the grammaticalization of a progressive aspectual marker in Dutch. Linguistics 49 (3). 479-524.

Flecken, Monique. 2011b. Event conceptualization by early bilinguals: Insights from linguistic as well as eye tracking data. Bilingualism: Language and cognition 14(1). 61-77.

Gullberg, Marianne \& Peter Indefrey. 2003. Language background questionnaire. Nijmegen: Max Planck Institute for Psycholinguistics.

Hilberink, Beryl, Ulrike Nederstigt \& Marianne Starren. In press. Grammatical preferences in aspect marking in L1 and L2: The case of L1 Dutch, English and German and L1 Dutch L2 English and L1 Dutch L2 German. Applied Psycholinguistics.

Ierland, Suzan van. 2010. Grammatical features influencing information structure: The case of L1 and L2 Dutch and English. Utrecht: Igitur (LOT dissertation series 245).

Jarvis, Scott \& Aneta Pavlenko 2008. Crosslinguistic influences in language and cognition. London: Routledge.

Klein, Wolfgang. 1994. Time in language. London: Routledge.

Krause, Olaf. 2002. Progressive Verbalkonstruktionen im Deutschen: Ein korpusbasierter Sprachvergleich mit dem Niederländischen und dem Englischen. Tübingen: Niemeyer.

Krifka, Manfred. 1995. Common nouns: A contrastive analysis of English and Chinese. In Gregory Carlson \& Jeffry Pelletier (eds.), The generic book, 398-411. Chicago: University of Chicago Press. 


\section{Gercoline van Beek, Monique Flecken and Marianne Starren}

Larsen-Freeman, Diane. 1991. Second language acquisition research: Staking out the territory. TESOL quarterly 25(2). 315-150.

Li, Ping, Sara Sepanski, \& Xiaowei Zhao 2006. Language history questionnaires: A web-based interface for bilingual research. Behavioral research methods 38. 202-210.

Lemmens, Maarten. 2005. Aspectual posture verb constructions in Dutch. Journal of Germanic linguistics 17(3). 183-217.

Levelt, Willem. 1989. Speaking: From intention to articulation. Cambridge: MIT Press.

Los, Bettelou \& Marianne Starren. 2012. A typological switch in early Modern English - and the beginning of one in Dutch? Manuscript submitted for publication.

Marian, Viorica, Henrike Blumenfeld \& Margarita Kaushanskaya. 2007. The Language Experience And Proficiency Questionnaire (LEAP-Q): Assessing language profiles in bilinguals and multilinguals. Journal of speech, language, and hearing research 50(4). 940-967.

Natale, Silvia. 2009. Gebrauchsdeterminanten der progressive Verbalperiphrase stare+gerundio. Tübingen: Narr.

Navarro, Samuel \& Elena Nicoladis. 2005. Describing motion events in adult L2 Spanish narratives. In David Eddington (ed.), Selected proceedings of the sixth conference on the acquisition of Spanish and Portuguese as first and second language, 102-107. Somerville, MA: Cascadilla Press.

Pottelberge, Jeroen van. 2004. Der am-progressiv. Tübingen: Narr.

Schmiedtová, Barbara \& Natalya Sahonenko. 2008. Die Rolle des grammatischen Aspekts in Ereignis-Enkodierung: Ein Vergleich zwischen tschechischen und russischen Lernern des Deutschen. In Patrick Gommes \& Maik Walter (eds.), Fortgeschrittene Lernervarietäten: Korpuslinguistik und Zweitspracherwerbforschung, 45-71. Tübingen: Niemeyer.

Schmiedtová, Barbara, Christiane von Stutterheim \& Mary Carroll. 2011. Language-specific patterns in event construal of advanced second language speakers. In Aneta Pavlenko (ed.), Thinking and speaking in two languages, 66-107. Clevedon: Multilingual matters.

Shirai, Yasuhiro. 2009. Temporality in first and second language acquisition. In Wolfgang Klein \& Ping Li (eds.), The expression of time, 167-193. Berlin: Mouton de Gruyter.

Slobin, Dan. 1996. From "Thought and language" to "Thinking for speaking". In John Gumperz \& Stephen Levinson (eds.), Rethinking linguistic relativity, 70-96. Cambridge: Cambridge University Press.

Slobin, Dan. 2000. Verbalized events: A dynamic approach to linguistic relativity and determinism. In Susanne Niemeier \& René Dirven (eds.), Evidence for linguistic relativity, 107-138. Amsterdam: Benjamins.

Starren, Marianne B. P. 2001. The second time: The acquisition of temporality in Dutch and French as a second language. Utrecht: Igitur (LOT dissertation series 50).

Stutterheim, Christiane von. 2003. Linguistic structure and information organisation: The case of very advanced learners. In Susan Foster-Cohen (ed.), EUROSLA Yearbook 3. 183-206. Amsterdam: Benjamins.

Stutterheim, Christiane von \& Ralf Nüse. 2003. Processes of conceptualization in language production: Language-specific perspectives and event construal. Linguistics 41. 831-881.

Stutterheim, Christiane von \& Mary Carroll. 2006. The impact of grammatical temporal categories on ultimate attainment in L2 learning. In Heidi Byrnes, Heather Weger-Guntharp, \& Katherine A. Sprang (eds.), Educating for advanced foreign language capacities, 40-53. Georgetown: Georgetown University Press.

Stutterheim, Christiane von. 2007. Sprachspezifische Prinzipien der Informationsverarbeitung. Paper presented at the Sprache und Denken Symposium of Humboldt University, Berlin.

Stutterheim, Christiane von, Mary Carroll \& Wolfgang Klein. 2009. New perspectives in analyzing aspectual distinctions across languages. In Wolfgang Klein \& Ping Li (eds.), The expression of time, 195-216. Berlin: Mouton de Gruyter.

Stutterheim, Christiane von, Martin Andermann, Mary Carroll, Monique Flecken \& Barbara Schmiedtová. 2012. How grammaticized concepts shape event conceptualization in language 
production: Insights from linguistic analysis, eye tracking data and memory performance. Linguistics 50(2). 833-867.

Talmy, Leonard. 2000. Toward a cognitive semantics. Cambridge: MIT Press.

Vismans, Roel, Matthias Hüning \& Fred Weerman (eds.). 2010. Dutch between English and German. [Special issue]. Journal of Germanic linguistics 22(4). 